\title{
A TEORIA DA APRENDIZAGEM SIGNIFICATIVA NAS PESQUISAS SOBRE FORMAÇÃO INICIAL E CONTINUADA DE PROFESSORES
}

\author{
THE MEANINGFUL LEARNING THEORY IN RESEARCH ON INITIAL AND \\ CONTINUING TEACHER EDUCATION
}

\author{
Evelyse dos Santos Lemos ${ }^{1}$, Luciana Abrão Lougon Soares ${ }^{2}$
}

Recebido: março/2021 Aprovado: maio/2021

\begin{abstract}
Resumo: Partindo do pressuposto de que o significado do conceito aprendizagem significativa é central na formação do profissional do ensino e que a teoria que o fundamenta é um referencial com grande potencial para subsidiar o ensino e a pesquisa sobre o ensino, nos questionamos sobre como a Teoria da Aprendizagem Significativa (TAS) vem sendo contemplada nos contextos educativos e no da sua investigação. Para tanto, analisamos artigos científicos que discutem a formação de professores, inicial e continuada, à luz desta teoria. Utilizamos a plataforma SciELO como base de dados e buscando artigos que continham os termos "aprendizagem significativa" e "formação de professores" em seus títulos, resumos e ou palavras-chaves. A ferramenta heurística "Vê de Gowin" foi nossa referência para análise e discussão dos dados, o que nos propiciou compreensão sobre o processo de produção do conhecimento de cada artigo e como os autores articularam a TAS na construção (e resolução) de seus problemas de investigação. Encontramos uma baixa frequência de estudos que discutem a formação de professores à luz da TAS e, mesmo nesses poucos artigos, a apropriação da teoria merece maior aprofundamento.

Palavras-chave: Teoria da aprendizagem significativa, saber docente, revisão da literatura, ensino de ciências
\end{abstract}

\begin{abstract}
Assuming that the meaning of meaningful learning concept is central in the education of teaching professionals and that the theory that underlies it is a reference with great potential to support teaching and research on teaching, we question how Meaningful Learning Theory (TAS) is being contemplated in educational contexts and in its investigation. Therefore, we analyzed scientific articles that discuss initial and continuing teacher education, in the light of this theory. We used the SciELO platform as a database in which we searched for articles with the terms "meaningful learning" and "teacher education" in their titles, abstracts and keywords. The "Gowin's Vee" heuristic tool was our reference for data analysis and discussion, which provided an understanding about the process of knowledge production in each article and how the authors articulated TAS in the construction (and resolution) of their problems of investigation. We found a low frequency of studies that discuss teacher education supported by TAS and, even in these few articles, the theory's appropriation deserves greater depth.
\end{abstract}

Keywords: meaningful learning theory, teacher Knowledge, literature review, science education

\section{Introdução}

Este trabalho faz parte de um estudo mais abrangente, voltado para a elaboração, implementação e avaliação de uma proposta de ensino para professores em exercício, cujo foco

1 (iD https://orcid.org/0000-0003-1024-5290 - Doutora em Ensino de Ciências pela Universidade de Burgos/Espanha. Docente no Programa de Pós-graduação Stricto Sensu em Ensino em Biociências e Saúde da Fiocruz. Membro do Grupo de Estudo e pesquisa em Aprendizagem Significativa (GEAS). Av. Brasil, 4365. 5 - Pavilhão Lauro Travassos, 2o andar, Manguinhos, CEP: 21040-360, Rio de Janeiro RJ, Brasil. CEP: 21.040-360. E-mail: evelyse@ioc.fiocruz.br

2 (iD https://orcid.org/0000-0002-8291-4257-Doutoranda no Programa de Pós-graduação Stricto Sensu em Ensino em Biociências e Saúde da Fiocruz. Membro do Grupo de Estudo e pesquisa em Aprendizagem Significativa (GEAS). Av. Brasil, 4365. 5 - Pavilhão Lauro Travassos, 2a andar, Manguinhos, CEP: 21040-360, Rio de Janeiro RJ, Brasil. CEP: 21.040-360. E-mail: lucaals@gmail.com 
é o favorecimento da aprendizagem significativa de conceitos das Biociências, incluindo os aspectos cognitivos, atitudinais e afetivos que nela interferem. Neste recorte, refletimos sobre o modo como a Teoria da Aprendizagem Significativa (TAS) vem sendo contemplada em estudos sobre formação docente que a assumem - ou fazem uso de seus conceitos - como referencial teórico.

Embora sejam muitos os estudos sobre formação de professores, o cotidiano da sala de aula segue priorizando a memorização à aprendizagem com significado (MOREIRA, 1999, 2011). As atividades da formação de professores, inicial e continuada, são momentos chave na socialização e configuração profissional e, no nosso entender, demandam uma concepção de aprendizagem que, conforme perspectiva construtivista, seja coerente com a fundamentada pela TAS. Junto à isso, como Nóvoa (1995) nos alertou, há décadas, a formação docente deve estimular uma perspectiva crítico-reflexiva, a qual forneça aos professores os meios de um pensamento autônomo. Uma outra premissa desse estudo é que a formação docente vai além da aquisição de técnicas e conhecimentos, construídos por acumulação de cursos. Ela se efetiva por meio de um trabalho de reflexão crítica sobre as práticas, e na construção permanente da identidade pessoal do professor.

Segundo Tardif (2014), o saber docente é plural, estratégico e composto de vários saberes, provenientes de diferentes fontes, tais como: os disciplinares, curriculares, profissionais (incluindo a ciência da educação e da pedagogia) e experienciais. Ainda de acordo com o referido autor,

[...]todo saber implica em um processo de aprendizagem e de formação; e, quanto mais desenvolvido, formalizado e sistematizado é um saber, como acontece com as ciências e os saberes contemporâneos, mais longo e complexo se torna o processo de aprendizagem, $o$ qual, por sua vez, exige uma formalização e uma sistematização adequadas[...] (TARDIF, 2014, p. 35).

Lecionar, sabemos, não é uma tarefa simples e, assim, requer uma formação complexa que transcenda o mero domínio do conteúdo específico e ou do conteúdo pedagógico (SHULMAN, 1986). O domínio do conteúdo é o que caracterizamos como saberes disciplinares, transmitidos nos cursos e instituições de ensino. Os saberes das disciplinas emergem da tradição cultural e social dos produtores de saberes. Já o domínio pedagógico apresenta-se como doutrinas ou concepções provenientes de reflexões sobre a prática educativa. São reflexões racionais e normativas que conduzem a sistemas mais ou menos coerentes de representação e de orientação da atividade educativa (TARDIF, 2014).

O professor ideal, segundo Tardif (2014), é aquele que conhece sua disciplina e seu programa, além de possuir conhecimentos relativos às ciências da educação e à pedagogia, condição para desenvolver um saber prático baseado em sua experiência cotidiana com seus alunos. Essas múltiplas articulações entre a prática docente e os saberes inerentes a ela, inserem os professores em um grupo social e profissional cuja existência depende de sua capacidade de dominar, integrar e mobilizar tais saberes enquanto condições para a sua prática. Em síntese, o exercício da docência requer formação especializada e profissional (TARDIF, 2014). 
Assim, ensinar um campo de conhecimento requer saberes específicos sobre a temática, sobre o conhecimento pedagógico e, principalmente, como destaca Shulman (1986), sobre o conhecimento pedagógico do conteúdo. É atuando nesta interseção, do conhecimento específico e do pedagógico, que o professor poderá exercer sua função com autonomia e êxito e, assim, terá maiores chances de ajudar seus alunos a aprenderem significativamente (AUSUBEL, 2003) as ideias centrais da disciplina e, por meio delas, interpretar os fenômenos que fazem parte de suas experiências cotidianas.

Nóvoa (1999) explica o ensino como prática social, por concretizar a interação entre professores e alunos que, com suas histórias pessoais, refletem a cultura e contextos sociais a que pertencem. Gowin (1981), por sua vez, ao inserir o "conteúdo" nessa relação, explicita o envolvimento de outros sujeitos, a exemplo dos autores dos materiais. A intervenção pedagógica do professor, bem como a aprendizagem do aluno, é influenciada pelo modo como eles pensam e agem à luz dos conhecimentos construídos nas diversas áreas/momentos de suas vidas.

Duso e Hoffmann (2013) defendem que cabe ao professor, o papel de incentivar o estudante a pesquisar e selecionar fontes confiáveis de informações, contrapor pontos de vistas diferentes e buscar os conhecimentos necessários, oportunizando que possam ser relacionados ao seu dia-a-dia. Sendo assim, a sala de aula deve se tornar um local de debates, no qual os estudantes possam participar ativamente demonstrando seus interesses e conhecimentos sobre diferentes assuntos, de variadas formas, olhares e pontos de vista.

No processo de escolarização não interessa qualquer tipo de aprendizagem. É preciso almejar e atuar com o compromisso de facilitar a aprendizagem significativa (AUSUBEL, 2003). Afinal, é o aprender com significado que possibilita ao sujeito agir com autonomia na sua realidade. Em decorrência, pode-se compreender a complexidade do processo do aprender e 0 de seu favorecimento por meio do ensino. De acordo com Gowin (1981) o evento educativo pode ser explicado como um evento no qual professor, material educativo e estudante, estabelecendo uma relação triádica, negociam e compartilham significados.

O ensino, de um modo geral, tem contribuído para a existência da aprendizagem mecânica (MOREIRA, 2011) porque a prática pedagógica vigente segue não considerando os conhecimentos prévios dos alunos e tampouco lhes apresenta um material potencialmente significativo ${ }^{1}$. Há que se destacar que a organização lógica do conteúdo escolar, relativamente comum nos programas de ensino, retrata uma lógica científica, nem sempre coerente com a lógica do aluno. Tais circunstâncias fazem com que os alunos tenham uma concepção inadequada de ensino, aprendizagem e conhecimento, como consequência de haverem sido acostumados a memorizar, definindo conceitos com frases prontas, sem saber explicar o significado das palavras citadas e, principalmente, por não terem sido acostumados a pensar sobre as informações as quais têm acesso.

${ }^{1}$ O material potencialmente significativo é aquele capaz de dialogar, de maneira apropriada e relevante, com o conhecimento prévio do estudante. A organização de um material de ensino potencialmente significativo requer que a relação entre a natureza do conhecimento do aluno e do conhecimento a ser ensinado seja considerada. Assim, o conteúdo a ser ensinado deve ser selecionado e organizado a partir das suas ideias centrais (LEMOS, 2006). 
Partindo do exposto, nos interessa conhecer que aspectos do fazer docente estão sendo privilegiados nos estudos que discutem a formação de professores na perspectiva da TAS e, a partir deles, analisar como a problemática vem sendo abordada no âmbito acadêmico e, particularmente, analisar que conceitos e princípios da TAS estão sendo priorizados. Em nossa busca, restrita à base de dados SciELO ${ }^{1}$, encontramos dezenove artigos que, simultaneamente, possuíam a formação de professores como foco central dialogando com a Teoria da Aprendizagem Significativa.

\section{Marco teórico}

Há quase seis décadas, em 1963, Ausubel publicou o livro "The Psychology of Meaningful Verbal Learning", no qual define aprendizagem e, fundamentado no conceito proposto, caracteriza a aprendizagem significativa como finalidade do processo educativo. Além disso, explicita as condições necessárias para a sua efetivação e apresenta princípios programáticos para favorecer sua ocorrência e avaliação (LEMOS, 2005).

Desde então a Teoria da Aprendizagem Significativa (TAS), na sua perspectiva original e com os aportes recebidos a partir de pesquisas desenvolvidas (MOREIRA, 1999, 2011; NOVAK, 2000; GOWIN, 1981), vem se mantendo como uma teoria atual e apropriada para subsidiar o processo educativo (MOREIRA, 1999, 2011) e também o processo da investigação sobre o ensino (LEMOS, 2012).

Aprender, na perspectiva da TAS, corresponde a um processo pessoal, intencional e progressivo no qual os novos significados (ideias) são relacionados aos conhecimentos previamente presentes na mente do aprendiz. É na atenção à natureza da relação entre o novo conhecimento e o prévio, que Ausubel (2003) nos esclarece que o processo da construção pessoal de conhecimento, a aprendizagem, permeia um continuum de relações literais e arbitrárias até relações substantivas e não arbitrárias. No primeiro caso, característico da aprendizagem mecânica, ou memorística, sendo relações literais e arbitrárias limitam a possibilidade de uso do (novo) conhecimento às situações já familiares. No segundo caso, da aprendizagem significativa, o conhecimento tem ampliada a sua possibilidade de uso para situações novas, conforme tais relações avançam no continuum, tornando-se não arbitrárias e ganhando substantividade (AUSUBEL, 2003).

Em outras palavras, aprender nunca é um fenômeno trivial e pode se efetivar como mera memorização ou como efetiva atribuição - pessoal - de significado. $O$ tipo de aprendizagem efetivada é diretamente dependente da intencionalidade do aprendiz para memorizar ou atribuir significado ao novo conhecimento, relacionando-o, de forma substantiva e não arbitrária, com os previamente presentes em sua estrutura cognitiva.

O ponto central da TAS, na proposta original, é o processo da facilitação da aprendizagem em contextos formais de ensino. De acordo com Lemos (2005), a teoria está no núcleo duro do

${ }^{1}$ A Scientific Electronic Library Online - SciELO é uma biblioteca eletrônica que abrange uma coleção selecionada de periódicos científicos brasileiros. A SciELO é o resultado de um projeto de pesquisa da FAPESP - Fundação de Amparo à Pesquisa do Estado de São Paulo, em parceria com a BIREME - Centro Latino-Americano e do Caribe de Informação em Ciências da Saúde. A plataforma SicELO está disponível no seguinte endereço eletrônico: https://search.scielo.org/advanced/?lang=pt 
construtivismo educativo porque esclarece o significado do aprender, caracteriza a aprendizagem significativa como finalidade do evento educativo, explicita as condições necessárias para a sua efetivação e apresenta princípios programáticos que favorecem a sua ocorrência e avaliação.

Ausubel (2003) defende que, dentre todos os fatores que influenciam a aprendizagem, o mais importante é aquele que o aluno previamente sabe. No entanto, desvendar o que o aluno já sabe é mais complexo do que a mera identificação de suas representações, conceitos e ideias. É fundamental considerar a totalidade do ser cultural/social em suas manifestações e linguagens corporais, afetivas e cognitivas. Para tanto, o professor deve estar atento aos vários aspectos que o aluno possa revelar.

Sendo assim, a organização do ensino requer que o conhecimento a ser aprendido seja bem analisado para que, respeitada a sua lógica interna, seja apresentado aos alunos as ideias centrais do tema, os conceitos estruturantes (GAGLIARDI, 1986). Definido o que deve ser ensinado, cabe ao professor aproveitar a lógica do conhecimento - prévio - do aluno como ponto de partida para decidir as estratégias e recursos instrucionais mais adequados para que aquele grupo particular de alunos tenha maiores chances de aprender significativamente.

Além da organização sequencial do conteúdo a ser ensinado, Ausubel (2003) propõe outros três princípios programáticos para ensinar, especificamente os da diferenciação progressiva, reconciliação integrativa e consolidação. A adequação destes princípios é diretamente dependente da relação entre a natureza do conhecimento prévio dos alunos e das novas ideias, considerando o caráter processual e recursivo da aprendizagem. Neste processo, o professor precisa, antes de apresentar as novas ideias, se certificar se os estudantes dispõem de subsunçores adequados. Na etapa do desenvolvimento do ensino o professor deve criar situações para que seus alunos possam refletir, negociar, captar, e compartilhar os significados do material educativo, ajudando-os a relacionar as novas informações aos conhecimentos prévios que possuem.

A avaliação, que permeia todas as etapas do evento educativo, finaliza o processo indicando se o objetivo - a aprendizagem do aluno - foi alcançado e se as estratégias e recursos adotados foram apropriados. Ou seja, a avaliação se compromete com o processo do ensino, com a aprendizagem do aluno e com a qualidade do ensino desenvolvido.

Portanto, conforme ressalta Novak (2000), a aprendizagem significativa é um conceito chave no processo educativo, pois parte do princípio que a educação é um conjunto de experiências cognitivas, afetivas e psicomotoras, que contribuem integradamente para a formação do indivíduo. No contexto educativo essa formação se dá, basicamente, pela aprendizagem dos vários campos disciplinares. Assim, considerando o cotidiano da escola, vale pensar sobre os aspectos que caracterizam as ações de ensino. $O$ referido autor, corroborando a relação triádica no evento educativo explicada por Gowin (1981), já mencionada, amplia o número destes elementos. Para ele, o evento educativo integra, de forma interdependente, cinco elementos: aprendiz, professor, conhecimento, contexto e avaliação.

Ainda segundo Novak (2000), aprendiz e professor interagem com o conhecimento, negociando-o com vistas a compartilhar significados, em um processo constantemente avaliado, 
que se efetiva em um contexto particular. Essa inter-relação e interação entre os elementos dão, a cada evento educativo, uma singularidade própria, sem possibilidade de repetição.

O papel da escola, nesta perspectiva, é promover situações que tenham o potencial de facilitar a aprendizagem significativa por parte dos alunos. Assim, é papel do professor ajudar o aluno a construir uma representação mental estável e organizada do novo conhecimento, ou seja, construir uma organização psicológica, porque é pessoal, mas que seja coerente com a lógica do conhecimento conforme aceito e compartilhado no campo disciplinar. Desta forma, como sintetizado por Lemos (2005, p. 43), "o processo educativo à luz da Teoria da Aprendizagem Significativa, corresponde a um contexto no qual indivíduos, que se percebem como sujeitos em permanente formação, ajudam outros sujeitos a se perceberem como tal e a autogeri-la, isto é, a aprender a aprender".

Uma das estratégias que podem ajudar na identificação de evidências de aprendizagem significativa dos alunos é a elaboração do diagrama Vê, instrumento heurístico proposto por Gowin em 1981. O Vê de Gowin, como é mais conhecido, é um diagrama na forma de "V", cuja construção se dá a partir de cinco questões norteadoras. Tais questões, na função original do recurso, auxiliam no "desempacotamento do conhecimento" expresso nos artigos científicos e resultam na interação entre dois domínios: um teórico conceitual e outro metodológico (MOREIRA, 2007). Quando adotado como recurso instrucional em sala de aula, permite ao aluno reconhecer o caráter humano, falível, provisório, da construção do conhecimento científico na busca de respostas à questões-foco. Segundo Moreira (2011) essa visão epistemológica é importante no ensino, pois todo evento educativo envolve a negociação e o compartilhamento de significados sobre algum conhecimento, processo que o aluno, com muita frequência, não percebe. No presente estudo nosso foco será a perspectiva epistemológica do Vê de Gowin, ou seja, será utilizado para analisar criticamente artigos de pesquisa.

\section{Metodologia}

A pesquisa sobre a formação de professores é multidisciplinar, "multimetodológica" e foi reconhecida como campo de pesquisa pela comunidade internacional de pesquisadores em Educação no início da década de 1970 (DINIZ-PEREIRA, 2019). Por ser uma linha de pesquisa consolidada, discutida em várias perspectivas e, portanto, com quantitativo de trabalhos expressivo, que dificultam uma análise geral, nos propusemos a analisar artigos que se ocupavam com a formação de professores, inicial ou continuada, cujo referencial teórico adotado tenha sido a Teoria da Aprendizagem Significativa (TAS).

Esta revisão foi desenvolvida em cinco etapas. Nosso primeiro critério foi trabalhar com artigos com acesso livre e publicados em revistas que usam avaliações às cegas, por isso optamos pela plataforma SciELO. Inicialmente buscamos textos, cujos resumos e/ou títulos e/ou palavras-chaves tivessem os termos "formação de professores" ou "formação docente" e, também, "aprendizagem significativa" (QUADRO 01). Os artigos encontrados foram numerados de 01 à 19, em ordem decrescente conforme ano da publicação. Ou seja, o artigo de número 01 
corresponde a publicação mais recente, do ano de 2020, e o artigo 19 corresponde ao mais antigo, ano de 2007 (ANEXO).

Na segunda etapa, caracterizamos os artigos, partindo das seguintes informações: ano de publicação, número de autores, instituição na qual os trabalhos foram desenvolvidos e assuntos abordados.

Tomando os títulos e resumos dos artigos como referência, como terceira etapa, categorizamos os mesmos em duas temáticas: pedagógico e disciplinar. A etapa seguinte envolveu a busca de conceitos específicos da TAS, apoiada na metodologia desenvolvida por Belmonte e Lemos (2008) (QUADRO 02).

A quinta e última etapa consistiu na análise dos artigos, utilizando o Vê de Gowin (1981) como referência, o que nos permitiu identificar: a problemática central (questão-foco), premissas teóricas e metodológicas (conceitos), metodologia (evento e transformações) e principais conclusões (asserção de conhecimento e de valor).

\section{Apresentação e discussão dos dados}

Coerente com o histórico da formação de professores como linha de pesquisa, nossa busca, realizada entre 1981 e 2020, encontrou 3.528 trabalhos publicados na plataforma SciELO. No entanto, somente 19 deles contemplaram o termo aprendizagem Significativa (QUADRO 01). Destes, apenas três artigos traziam o conceito "aprendizagem significativa" (AS) no título, resumo e palavra-chave. Dez artigos mencionaram o conceito apenas no resumo e seis no resumo e palavra-chave.

Quadro 01: Quadro geral com os descritores pesquisados na plataforma SciELO.

\begin{tabular}{|c|c|c|c|c|c|c|c|}
\hline $\begin{array}{l}\text { Descritor } \\
\text { Principal }\end{array}$ & Total & $\begin{array}{c}\text { Descritor } \\
\text { principal } \\
\text { (locais } \\
\text { específicos } \\
\text { do texto) }\end{array}$ & Total & $\begin{array}{c}\text { Descritor } \\
\text { Principal + } \\
\text { Combinação } 01\end{array}$ & Total & $\begin{array}{l}\text { Descritor Principal + } \\
\text { Combinação } 01 \\
\text { (locais específicos do } \\
\text { texto) }\end{array}$ & Total \\
\hline \multirow{8}{*}{$\begin{array}{c}\text { Formação } \\
\text { de Profes- } \\
\text { sores }\end{array}$} & \multirow{8}{*}{3528} & Título & 864 & \multirow{2}{*}{$\begin{array}{l}\text { Formação } \\
\text { continuada } \\
\text { (todos os } \\
\text { índices) }\end{array}$} & \multirow{2}{*}{450} & $\begin{array}{c}\text { Formação Continuada } \\
\text { (título) }\end{array}$ & 140 \\
\hline & & Resumo & 2774 & & & $\begin{array}{c}\text { Formação continuada } \\
\text { (resumo) }\end{array}$ & 118 \\
\hline & & & & \multirow{2}{*}{$\begin{array}{l}\text { Formação Inicial } \\
\text { (todos os } \\
\text { índices) }\end{array}$} & \multirow{2}{*}{657} & $\begin{array}{c}\text { Formação Inicial } \\
\text { (título) }\end{array}$ & 214 \\
\hline & & & & & & $\begin{array}{l}\text { Formação Inicial } \\
\text { (Resumo) }\end{array}$ & 130 \\
\hline & & & & \multirow{2}{*}{$\begin{array}{l}\text { Aprendizagem } \\
\text { (todos os } \\
\text { índices) }\end{array}$} & \multirow[b]{2}{*}{790} & Aprendizagem (título) & 160 \\
\hline & & & & & & $\begin{array}{l}\text { Aprendizagem } \\
\text { (resumo) }\end{array}$ & 137 \\
\hline & & & & \multirow{2}{*}{$\begin{array}{l}\text { Aprendizagem } \\
\text { Significativa } \\
\text { (todos os } \\
\text { índices) }\end{array}$} & \multirow{2}{*}{19} & $\begin{array}{c}\text { Aprendizagem } \\
\text { Significativa (título) }\end{array}$ & 03 \\
\hline & & & & & & $\begin{array}{c}\text { Aprendizagem } \\
\text { Significativa (resumo) }\end{array}$ & 19 \\
\hline
\end{tabular}


Estes artigos foram publicados entre os anos de 2007 e 2020, em quatorze periódicos científicos, são eles: Revista Electrónica de Investigación em Educación en Ciencias ( $n=03$ ); Ciência \& Educação ( $n=02)$; Revista Científica $(n=02)$; Revista Iberoamericana para la Investigación y el Desarrollo Educativo ( $n=02)$; Interface Comunicação Saúde e Educação ( $n=01$ ); Associação Brasileira de Psicologia Escolar e Educacional ( $n=01$ ); Avaliação: Revista da Avaliação da Educação Superior ( $n=01$ ); Educar em Revista ( $n=01$ ); Revista Brasileira de Educação Médica $(n=01)$; Hallazgos ( $n=01)$; Cuadernos de Investigación Educativa $(n=01)$; Estudos avançados $(n=01)$; Entramado $(n=01)$; e, Revista Cuidarte $(n=01)$. Ainda que o número de artigos seja mínimo no conjunto dos textos ocupados com formação docente, vale destacar a diversidade de revistas e autores entre esses 19 artigos, podendo ser um indicador da potencialidade da teoria como referência para o ensino e sua investigação. Todos os periódicos, conforme seus respectivos textos de apresentação, têm como missão comum promover, divulgar e socializar pesquisas cujo foco é o ensino e a aprendizagem de Ciências.

Coerente com o perfil da plataforma SciELO, biblioteca eletrônica que abrange uma coleção selecionada de periódicos científicos brasileiros e estrangeiros, a maioria dos autores são da América do Sul, sendo onze do Brasil, quatro da Colômbia e um do Chile. A América do Norte está representada com autores mexicanos $(n=03)$. No Brasil a predominância de trabalhos é desenvolvida por pesquisadores da região Sudeste do país $(n=08)$, seguido pela região Nordeste $(n=02)$ e Sul $(n=01)$. Dos dezenove artigos analisados, apenas três foram escritos por um único autor, dez por dois e os demais por três ou mais autores. A maioria foi escrita em português ( $n=11$ ) e os demais ( $n=08$ ) na língua espanhola.

No que concerne à apropriação da TAS, inferida pela presença do conceito "aprendizagem significativa", poucos são os artigos que citam os textos originais e ou os autores mais representativos da mesma (Ausubel, Novak, Gowin e Moreira). A ausência de textos representativos, especialmente os originais, pode ser uma explicação para algumas das incoerências encontradas nos trabalhos como se verá a seguir. Por outro lado, ainda que não seja o escopo deste trabalho, não podemos ignorar que a apresentação de referências, infelizmente, não é garantia de efetiva leitura.

Ainda visando um panorama geral, buscamos as temáticas disciplinares, nível de escolaridade (da educação básica ao ensino superior) contemplados nos artigos. Coerente com o foco das revistas no ensino de Ciências, os artigos abordam os seguintes campos disciplinares: Ciência da Saúde $(n=08)$, Biologia $(n=04)$; Matemática $(n=02)$; Física $(n=01)$; Educação Física $(n=01)$. Também identificamos três artigos, incluídos na categoria pedagógica que, embora vinculados à assuntos das Ciências Naturais, focavam questões pedagógicas.

Em relação ao nível de escolaridade, a maioria dos trabalhos se preocupa com a formação do professor no ensino superior $(n=16)$. Ainda que nossa amostra não seja representativa, essa predominância nos parece preocupante por sugerir maior atenção à formação inicial do que à continuada do professor. Afinal, é sabido que as concepções de ensinar e aprender que os futuros professores apresentam quando ingressam no curso superior, em geral equivocadas, pouco alteram nessa etapa da formação. Concordamos com Lemos (2005), ao afirmar haver 
desatenção à origem dos problemas, e, que o maior desafio, no momento em que a escola começa a ser percebida como unidade formadora de todos os seus sujeitos, é melhorar a comunicação entre os pares e otimizar a formação continuada.

Assumindo a concepção de aprender proposta e fundamentada pela TAS como essencial na formação do professor e que a coerência entre teoria e prática extrapola a mera menção dos termos e ou referenciais, nos propusemos a identificar como este referencial vem sendo apropriado no contexto do ensino e da pesquisa sobre o ensino. Assim, antes de leitura sistematizada dos textos, quantificamos a presença dos conceitos centrais da TAS em cada artigo, usando como referência Lemos et al, 2010 (QUADRO 2). Esses dados nos permitiram observar que conceitos estão sendo priorizados nos estudos que discutem formação docente na perspectiva da TAS.

Ainda que a teoria abranja muitos conceitos, todos importantes, consideramos como centrais para refletir a formação docente, aqueles que, como antecipado, definem a aprendizagem, o ensino e orientam a construção do material do ensino e a dinâmica inerente às situações de ensino efetivamente comprometidas com a facilitação da aprendizagem significativa (LEMOS, 2005). Deste modo, nos parece coerente que aprendizagem significativa seja bastante enfatizada, ainda que a quarta parte dos artigos analisados faça uso pontual do termo, com até três menções. Trata-se do conceito central da teoria, cujo significado, subjacente às teorias construtivistas (MOREIRA, 1997) é essencial para uma prática educativa que tenha o potencial de favorecer a representação mental - pessoal - do novo conhecimento. No mesmo sentido, ainda que não seja um termo - ou prática - exclusiva da TAS, a grande atenção atribuída à avaliação nesse conjunto de trabalhos merece enaltecimento, mesmo que a mera frequência não seja garantia de efetiva atenção às evidências de aprendizagem significativa.

Diante do exposto, nos parece razoável que os tipos de aprendizagem significativa "representacional", "conceitual", "proposicional", "subordinada", "superordenada", "combinatória" - não tenham tido destaque nos estudos. Por outro lado, ao explicar que importante é o processo, sua compreensão, o modo como acontece (ou pode ser favorecida) a aprendizagem - "por descoberta", "por recepção" -, seria desejável maior atenção aos princípios programáticos e recursos instrucionais. Sem entrar na discussão sobre como Ausubel abordou a aprendizagem por descoberta na proposição da teoria, nos parece importante destacar o desequilíbrio entre a potencial contribuição da teoria para a organização do ensino e avaliação da aprendizagem - e a frequência de conceitos a eles relacionados.

Não há, no nosso entender, como fundamentar o perfil do profissional docente, sem profunda atenção aos contextos de ensino e mencionando pontualmente aspectos como: correlação (continuum) entre aprendizagem significativa e mecânica; análise da natureza do conhecimento envolvido (conteúdo das disciplinas); papel do aluno na disposição para aprender, negociação e compartilhamento de significados; elaboração do material de ensino potencialmente significativo integrando atenção ao conhecimento prévio, subsunçores, ideias centrais, princípios programáticos, recursos e estratégias instrucionais; dentre outros. 
Em síntese, ainda que um mero levantamento de termos não nos autorize qualificar qualquer estudo, a frequência e distribuição aqui encontradas nos induz a questionar se a TAS está, de fato, fundamentando os estudos identificados.

Quadro 2 - Termos e conceitos da Teoria da Aprendizagem Significativa e suas respectivas frequências nos trabalhos analisados. Adaptado de Lemos et al, 2010.

\begin{tabular}{|c|c|c|c|c|}
\hline \multicolumn{2}{|c|}{ Conceitos } & \multirow{2}{*}{$\begin{array}{l}\text { Trabalhos que contemplam os conceitos (e } \\
\text { respectiva frequência) } \\
\qquad 17(01)\end{array}$} & \multirow{2}{*}{$\begin{array}{c}\begin{array}{c}\text { frequência } \\
\text { total dos } \\
\text { conceitos }\end{array} \\
01\end{array}$} & \multirow{2}{*}{ 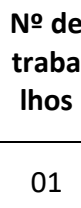 } \\
\hline 1 & Aprendizagem combinatória & & & \\
\hline 2 & Aprendizagem conceitual & - & - & - \\
\hline 3 & Aprendizagem mecânica & $11(05)-13(06)-19(01)$ & 12 & 03 \\
\hline 4 & Aprendizagem por descoberta & - & - & - \\
\hline 5 & Aprendizagem proposicional & - & - & - \\
\hline 6 & Aprendizagem receptiva & - & - & - \\
\hline 7 & Aprendizagem representacional & - & - & - \\
\hline 8 & Aprendizagem significativa & $\begin{array}{c}01(16)-02(03)-03(04)-04(04)-05(01)-06(01) \\
-07(01)-08(07)-09(13)-10(01)-11(25)- \\
12(04)-13(40)-14(08)-15(05)-16(05)-17(17) \\
-18(02)-19(12)\end{array}$ & 169 & 19 \\
\hline 9 & Aprendizagem superordenada & - & - & - \\
\hline 10 & Aprendizagem subordinada & - & - & - \\
\hline 11 & Assimilação & $01(01)-05(03)-07(01)-13(01)-15(01)-17(03)$ & 10 & 06 \\
\hline 12 & Avaliação & $\begin{array}{c}01(08)-02(81)-03(10)-05(14)-06(16)-07(07) \\
-08(08)-09(10)-11(03)-12(09)-13(07)- \\
14(31)-16(02)-17(02)-18(05)-19(07)\end{array}$ & 220 & 16 \\
\hline 14 & Evidências de aprendizagem & - & - & - \\
\hline 15 & Conhecimento(s) prévio(s) & $\begin{array}{c}01(06)-03(01)-04(01)-07(01)-11(02)-13(02) \\
-14(01)-17(01)\end{array}$ & 15 & 08 \\
\hline 16 & Subsunçor(es) & $11(02)-13(03)-15(01)-17(05)$ & 11 & 04 \\
\hline 17 & Consolidação & 01(01) & & \\
\hline 18 & Diferenciação progressiva & 19(01) & 01 & 01 \\
\hline 19 & Organização sequencial & - & - & - \\
\hline 20 & $\begin{array}{l}\text { Reconciliação integrativa / } \\
\text { Reconciliação Integradora }\end{array}$ & 19(04) & 04 & 01 \\
\hline 21 & (Pre)disposição para aprender & $13(01)$ & 03 & 01 \\
\hline 22 & Intencionalidade & $13(32)$ & 32 & 01 \\
\hline 23 & $\begin{array}{l}\text { Material Potencialmente } \\
\text { Significativo }\end{array}$ & $15(01)-19(03)$ & 04 & 02 \\
\hline 24 & Negociação de significados & $13(08)$ & 08 & 01 \\
\hline 25 & Compartilhamento & $01(04)-05(02)-13(02)-16(01)-18(01)$ & 10 & 05 \\
\hline 26 & Ideias Centrais & $13(01)$ & 01 & 01 \\
\hline 27 & Mapas Conceituais & 19(05) & 05 & 01 \\
\hline 28 & Vê de Gowin & - & - & - \\
\hline 29 & Organizador(es) prévio(s) & $17(02)-19(03)$ & 05 & 02 \\
\hline 30 & $\begin{array}{l}\text { Resolução de problemas } \\
\text { (solução de problemas) }\end{array}$ & $\begin{array}{c}01(03)-05(01)-07(02)-08(02)-09(03)-11(02) \\
-12(01)-14(02)-15(01)-19(01)\end{array}$ & 10 & 07 \\
\hline
\end{tabular}


Para analisar como a TAS está contemplada nos estudos selecionados, utilizamos os elementos do Vê de Gowin (GOWIN, 1981), ferramenta epistemológica que, como antecipado, possibilita o reconhecimento da coerência teórico metodológica dos textos e, em decorrência, dos estudos neles contemplados. No entanto, destacamos não ser nosso objetivo avaliar os estudos envolvidos. Ao contrário, nos interessa saber se a potencial contribuição desta teoria para o processo educativo - na formação do professor e do aluno - está sendo percebida e utilizada.

Como nosso próprio levantamento indica, são incontáveis o número de estudos que discutem formação de professores, mas são pouquíssimos os que assumem a TAS como aporte teórico. Também é sabido que o levantamento de estudos por meio de descritores nem sempre oferece a busca desejada ou a realidade. Não foi diferente no nosso caso. No que concerne à formação docente, somente 07 (artigos 01, 03, 04, 11, 12, 13 e 16) dos 19 estudos analisados estão efetivamente ocupados com o tema. Nos demais, a formação docente aparece com tema secundário, em geral, mencionada para destacar a importância da mesma para o sucesso de alguma intervenção pedagógica ou mesmo do processo educativo como um todo.

Tal fato, com certeza, explica parte das discrepâncias apontadas no levantamento quantitativo dos conceitos (QUADRO 2). Outra possível explicação pode estar no uso de conceitos da teoria para expressar ideias que não decorrem da mesma, como é o caso do conceito aprendizagem significativa, muitas vezes utilizado sem relação com a teoria que o fundamenta. A polissemia deste conceito (LEMOS, 2012; MOREIRA, 1999, 2011), bastante (re)conhecida, é uma das motivações do presente estudo. Consideramos fundamental - e necessário - que a aprendizagem significativa esteja presente no contexto educativo, porém com significado coerente com o fundamentado na TAS. Por outro lado, como é o caso do texto de Araújo e Vieira, 2013, (artigo número 12) cujo foco foi discutir práticas docentes a partir de Carl Rogers, que acabou selecionado por meio do nosso critério de busca ainda que não estivesse no escopo deste estudo. Mesmo que os argumentos das autoras, pela correspondência entre as duas teorias, ambas sob o paradigma construtivista (MOREIRA, 1997), sejam bastante coerentes entre si, principalmente no que diz respeito à intencionalidade do aluno para aprender e à importância da negociação de significados em sala de aula. No entanto, ainda que "aprendizagem significativa" seja mencionada quatro vezes no texto, não há razão para reclamar a presença da TAS na discussão. Simplesmente não foi a proposta do texto.

Entretanto, encontramos oito trabalhos (artigos: 01, 03, 09, 11, 13, 15, 17, e 19) que consideramos coerentes com a TAS porque, na articulação entre discussão e resultados, utilizam argumentos, conceitos, e princípios da teoria. Destacamos o trabalho das autoras Belmont e Lemos (2012) - artigo 13 - cujo objetivo era compreender se o tipo de interação que os alunos estabelecem entre si, com o professor e com o conhecimento ensinado favoreceu a aprendizagem significativa pelos mesmos. Este artigo se destaca pelo maior número de conceitos articulados referentes à TAS (QUADRO 02). As autoras ressaltam a importância da intencionalidade para se aprender significativamente e por isso, buscaram identificar as ações dos alunos ao longo da disciplina no processo de aprendizagem. Seus indicadores para perceberem as evidências de aprendizagem significativa foram variados e contemplaram os cinco elementos do evento educativo (NOVAK, 2000), a saber: (a) a participação nas aulas, (b) 
a natureza das interações verbais entre professor e alunos, (c) as situações de interação que se caracterizaram como negociação de significados, (d) os hábitos de estudo, (e) o contato com o professor para esclarecer dúvidas em horários extraclasse, (f) o pedido de tarefas extras às solicitadas pelo professor, e por último, (g) a avaliação do professor sobre as atitudes dos alunos no decorrer da disciplina.

Outro trabalho que se destacou positivamente foi o artigo número 11 , das autoras Infante-Malachias e Santos (2013), cuja questão-foco era compreender se a utilização de modelos didáticos analógicos promove a aprendizagem significativa crítica. As autoras utilizaram a Teoria da Aprendizagem Significativa Crítica (MOREIRA, 1999, 2011) para argumentar que o exercício metacognitivo realizado por estudantes na elaboração de analogias e de suas respectivas justificativas pode promover e facilitar a aprendizagem significativa crítica dentro do contexto da sala de aula.

Resumindo o que foi dito, a presente análise, orientada pelo Vê epistemológico (GOWIN, 1981) nos propiciou entender a compreensão acerca do processo de produção do conhecimento de cada estudo, e, principalmente, como os autores articulavam suas pesquisas, seus dados e tomadas de decisões com a TAS.

Infelizmente, ainda que próximo do que imaginávamos, verificamos, nessa análise, que a relação entre a natureza do conhecimento, o perfil do aluno, do professor e do contexto de ensino é pouco presente, ou mesmo ausente, nas justificativas das intervenções e/ou nas análises dos dados obtidos. Do mesmo modo, raramente as evidências de aprendizagem significativa são apresentadas, aspecto que, de acordo com a TAS, são essenciais para validar o progresso da aprendizagem e, em decorrência, a qualidade do ensino relacionado (AUSUBEL, 2003). Por consequência, não nos surpreende que o delineamento metodológico apresentado nos textos não reflete, em sua maioria, o discurso teórico apresentado na parte inicial dos mesmos. Também podemos relacionar a baixa frequência de conceitos centrais da TAS por sua presença estar limitada ao item "marco teórico". Para ganhar coerência não basta defender uma filosofia construtivista do conhecimento, é importante que a mesma oriente a prática, seja do ensino ou da sua investigação (LEMOS, 2005).

Consideramos importante destacar que, apesar da alta menção ao conceito aprendizagem significativa, o caráter processual, dinâmico e recursivo da aprendizagem foi pouco contemplado neste conjunto de trabalhos. Tal fato, somado à ênfase nas estratégias de ensino, parece sugerir que o significado de aprendizagem significativa que está orientando as investigações é pouco coerente ao proposto por Ausubel e corroborado por estudos mais recentes sobre a TAS. Dentre os trabalhos que trazem aspectos (conceitos) da teoria mas não a tomam efetivamente como base teórica para sua discussão, as principais incoerências são percebidas pela ausência da teoria na apresentação de seus resultados e discussões, bem como pela ausência de menção aos autores da teoria (Ausubel, Novak, Gowin e Moreira).

Tomando como exemplo a atenção às metodologias de ensino e recursos instrucionais, podemos citar o artigo 16, (PACCA e SCARINCI, 2010), que reflete sobre a importância da aula expositiva para a aprendizagem significativa na perspectiva do que pensam os professores. Apesar do destaque, no título, do conceito "aprendizagem significativa", que aparece 05 vezes 
no corpo do texto, os demais termos considerados como da teoria que estão contemplados são avaliação ( $n=02)$, compartilhamento $(n=01)$ e concepções alternativas $(n=01)$. Ou seja, como enfatizado acima, no marco teórico, o potencial de favorecer a aprendizagem significativa não se limita à escolha da estratégia de ensino. Há um conjunto de elementos que, interdependente relacionados, determinam o "sucesso ou fracasso" da aprendizagem almejada a partir do ensino realizado. Compreender a qualidade da aprendizagem efetivada demanda reflexão do processo à luz da TAS.

No caso da PBL, estratégia muito coerente com a TAS, o trabalho 07, de Sanabria e Riobueno (2017), apresenta a percepção de alunos do programa de Regência de Farmácia na utilização da metodologia da aprendizagem baseada em problema. Para os autores a PBL é baseada em um método de investigação assumido como essencial para desenvolver um pensamento crítico, além de melhorar a compreensão dos temas vistos em sala para resolver problemas em ações cotidianas. Embora muito coerente com a teoria, a contribuição poderia ser ainda maior se mais de seus conceitos e princípios específicos estivessem presentes na discussão. Só utilizaram os conceitos aprendizagem significativa $(n=01)$, assimilação $(n=01)$, avaliação $(n=07)$, conhecimento prévio $(n=01)$, resolução de problemas $(n=01)$ e solução de problemas $(n=01)$. Ainda sobre percepções dos estudantes, o artigo 10 , de Bulgarelli e colaboradores (2014), apenas menciona a aprendizagem significativa ao afirmarem que o SUS é um rico espaço de aprendizagem para a formação de profissionais da saúde, mas não esclarecem como.

No trabalho 05, de Mauricio e Aguirre (2018) cujo objetivo foi destacar o impacto da utilização da "Tecnologia, Informação e Comunicação (TIC)" no processo de ensino e aprendizagem da matemática, os autores afirmam que o uso da TIC não pode ser visto como um substituto do trabalho do professor. Para os autores, centrados na avaliação (14 menções) e valorizando o processo de assimilação $(n=03)$ e o compartilhamento $(n=02)$, a contribuição da TIC como recurso instrucional corresponde a mais uma estratégia para motivar os alunos a experimentarem os conceitos trabalhados através de simulações e ferramentas interativas.

Já no trabalho de Melo e colaboradores (2008), artigo 18, cujo objetivo foi oferecer formação integradora na área de genética médica aos graduandos de medicina, o favorecimento da aprendizagem está relacionado, coerentemente, à diversificação do cenário de ensino e aprendizagem. De acordo com os autores, centrados nos conceitos avaliação $(n=5)$ e compartilhamento ( $n=01$ ), que não são exclusivos da TAS, os estudantes se aproximaram mais da realidade dos pacientes com deficiência mental e constataram as implicações dos fundamentos teóricos na prática clínica, tornando a aprendizagem significativa.

Como se depreende do que foi apresentado até aqui, a mera menção do conceito aprendizagem significativa não significa reflexão à luz da TAS. No entanto, corroborando a ideia de que os conceitos e princípios da teoria compõem o núcleo duro do paradigma construtivista (LEMOS, 2005), a atenção ao caráter pessoal e processual da aprendizagem já tendem a favorecer uma prática e reflexão coerente com a teoria. Pacca e Villani (2018), por exemplo, falam da importância do diálogo em sala de aula, da atenção ao aluno e ao contexto no qual está inserido, do planejamento das aulas, da importância dos conhecimentos prévios dos alunos 
para se ensinar o tema proposto. Apesar de bastante coerentes com a TAS, os autores não a exploram como referencial. Os pesquisadores, valorizando o lugar das concepções de aprendizagem na orientação dos procedimentos adotados e desenvolvidos para o planejamento e a realidade em sala de aula, defendem a formação continuada dos professores, além de sugerir a constante reformulação das aulas conforme a necessidade de quem está aprendendo.

Dois trabalhos (artigos 02 e 14) trouxeram a avaliação como destaque. O trabalho de Costa et al (2011), propõe a avaliação da prática profissional como estratégia de ensino e aprendizagem. Para eles os cenários simulados facilitam a aprendizagem significativa, além de favorecer a integração das unidades educacionais e o desenvolvimento das competências profissionais. Diferente dos demais, os autores, em vários momentos, destacam a importância da aprendizagem significativa para a formação dos integrantes do espaço educativo (alunos, professores e formadores de professores) e não somente do aluno. No mesmo sentido, o trabalho 02, de Garcia e colaboradores (2019), cujo objetivo foi refletir sobre as concepções avaliativas da aprendizagem e as suas influências nas práticas avaliativas, afirmam que as concepções de professores e alunos têm uma relevância recíproca. Ou seja, enquanto os professores são responsáveis por avaliar o processo de avaliação e determinar se a aprendizagem significativa foi alcançada; cabe aos estudantes, a partir da concepção de saber, atuarem como agentes ativos no processo de avaliação. Desta forma, mesmo sem destacar seu caráter processual, defendem que a avaliação, mais do que um instrumento, é um meio para determinar as fraquezas e as forças que tanto o professor quanto os alunos possuem.

Os aspectos afetivos, mesmo que sem diálogo explícito com a TAS, também aparecerem. O artigo 06, de Laredo (2018), teve como objetivo estudar a saúde ocupacional de professores de ensino superior e afirmando sua importância no processo da promoção da aprendizagem significativa dos alunos. Embora foque apenas o professor, alegando maior propensão a desenvolver doenças desencadeadas pelo estresse em comparação com outras profissões, destaca a interferência dos sentimentos na qualidade do processo educativo. Ainda relacionado aos aspectos afetivos, bem como aos contextuais, Salazar e Flores (2016), artigo 08, discutem a disponibilidade para aprendizagem interprofissional assumindo-a como importante ferramenta para o desenvolvimento de competências colaborativas na formação dos estudantes na área de saúde. Alegam favorecer a aprendizagem significativa por envolver o respeito à outras profissões, ao planejamento conjunto, o exercício da tolerância e a negociação.

O contexto, implicitamente presente no artigo 08, Salazar e Flores (2016), também está contemplado no artigo 05, de Mauricio e Aguirre (2018), quando afirmam que para utilizar a TIC como recurso em sala de aula, no processo de ensino e aprendizagem da matemática, é necessário gerar condições de uso tanto do professor quanto do aluno.

As reflexões realizadas, ainda que denunciem pequena atenção aos pressupostos da teoria da aprendizagem significativa nos textos analisados, parecem nos autorizar a supor que o uso do conceito pode ser indicador de tendência de atenção ao caráter pessoal e processual da aprendizagem. Tal fato, no nosso olhar, não elimina a importância de real apropriação da teoria por sua potencialidade para subsidiar o fazer docente efetivamente comprometido com a aprendizagem significativa. 


\section{Considerações finais}

Muito embora a Teoria da Aprendizagem Significativa seja um referencial fundamental para orientar a prática educativa e a da sua investigação (LEMOS, 2005), a sua presença, nestes dois contextos ainda demanda atenção e reconhecimento. O levantamento e análise aqui realizados, longe de ser representativo, porque limitado à plataforma SciELO, corrobora nossa percepção de que apropriação da teoria merece maior atenção. É muito baixa frequência de artigos que se preocupam com a formação de professores à luz da Teoria, apesar da menção explícita ao conceito "aprendizagem significativa". Em geral, ainda que os estudos afirmem a ocorrência da aprendizagem significativa, não apontam as evidências necessárias à tal afirmação e a análise do processo educativo pouco esclarecem sobre os fatores que promovem ou dificultam a evolução dos conhecimentos dos alunos.

Nesse sentido, indicando uma apropriação superficial da TAS, a mera menção dos conceitos e ou princípios, sem adequado esclarecimento dos pressupostos e caminho metodológico, refletem certa fragilidade teórico-conceitual nos estudos. No entanto, também é possível perceber, mesmo sem efetiva apropriação da teoria, alguma preocupação com o caráter pessoal e processual da aprendizagem, assim como atenção à sua avaliação.

O processo da atribuição do significado requer do aprendiz intencionalidade para perceber a informação, interpretá-la, representá-la mentalmente e construir, ao longo do processo, representações externas que reflitam, da melhor maneira possível, os significados que aprendeu. $\mathrm{O}$ ensino, por sua vez, para ter o potencial de favorecer este tipo de aprendizagem, deve garantir que as ideias em questão, prévias e novas, sejam negociadas e compartilhadas. Sem concebermos o aprender nessa perspectiva, pouca chance teremos de otimizar a qualidade do ensino, da formação escolar e do aporte científico ao contexto das escolas.

\section{Referências}

AUSUBEL, D.P., NOVAK, J.D., HANESIAN, H. Psicologia Educacional. 2ed. Rio de Janeiro: Interamericana, 1980.

AUSUBEL, D.P. Aquisição e Retenção de Conhecimentos: uma perspectiva Cognitiva. Lisboa: Plátano, 2003.

BELMONT, R.S. e LEMOS, E.S. A aprendizagem significativa nos trabalhos apresentados no $1^{\circ}$ Encontro Nacional de Aprendizagem Significativa: reflexões iniciais. $2^{\circ}$ Encontro de Aprendizagem Significativa ( $2^{\circ}$ ENAS), 24-28 de novembro de 2008, Canela, Rio Grande do Sul, p. 127-138.

DUSO, L. e HOFFMANN, M. B. A discussão das controvérsias sociocientíficas na pesquisa em educação em ciências: uma revisão narrativa a partir de periódicos no brasil. Ensino de Ciências e Tecnologia em Revista. V. 3 n, 2 p. 66-85, 2013.

GAGLIARDI, R. Los conceptos estructurales en el aprendizaje por investigación. Enseñanza de las ciencias. v. 4 n, 1, p. 30-35, 1986. 
GOWIN, D.B. Educating. New York: Cornell University Press, 1981.

LEMOS, E. S. Enseñanza el hacer docente: reflexiones a la luz de la teoría del aprendizaje significativo. Aprendizagem Significativa em Revista/Meaningful Learning Review. V. 2 n, 2 p. 23-41, 2012.

El aprendizaje significativo y la formación inicial de profesores de Ciencias y Biología. Burgos, 2008. 345f. Tese (Doutorado em Ensino de Ciências) - Universidade de Burgos, Burgos, 2008.

- (Re)Situando a Teoria de Aprendizagem Significativa na Prática Docente, na Formação de Professores e nas Investigações Educativas em Ciências. Revista Brasileira De Pesquisa Em Educação Em Ciências. v. 5 n. 3, p.38 51, 2005.

MOREIRA, M. A. Teorias de aprendizagem. São Paulo: EPU, 2011. (Obra original publicada em (1999).

MOREIRA, M. A. Aprendizagem significativa: um conceito subjacente. Em Moreira, M.A., Caballero, M.C. e Rodríguez, M.L. (orgs.) (1997). Actas del Encuentro Internacional sobre el Aprendizaje Significativo. Burgos, España. pp. 19-44.

NÓVOA, Antonio (Org). Vidas de professores. 2. ed. Porto: Porto, 1995

Profissão professor. 2. Ed. Porto: Porto, 1999.

NOVAK, J. D. Aprender, Criar e utilizar o conhecimento: mapas conceituais como ferramentas de facilitação nas escolas e empresas. Lisboa: Plátano, 2000.

SHULMAN, L.S. Those who understand: knowledge growth. Teaching Educational Researcher, v. 15 n, 2 p. $4-14,1986$.

TARDIF, M.; Saberes docentes e formação profissional. Petrópolis: Vozes, 2014.

\section{Anexo}

Artigos encontrados na plataforma SciELO, cujos títulos e/ou palavras-chaves tivessem especificamente a palavra "formação de professores" e "aprendizagem significativa".

\begin{tabular}{|c|c|c|c|}
\hline Cód. & Título & Autores & $\begin{array}{c}\text { Ano de } \\
\text { Publicação }\end{array}$ \\
\hline 01 & $\begin{array}{l}\text { La formulación de preguntas como estrategia didáctica } \\
\text { para motivar la reflexión en el aula }\end{array}$ & Claudine Glenda Benoit Ríos & 2020 \\
\hline 02 & $\begin{array}{l}\text { Reflexiones docentes acerca de las concepciones sobre la } \\
\text { evaluación del aprendizaje y su influencia en las prácticas } \\
\text { evaluativas }\end{array}$ & $\begin{array}{l}\text { Elvira Patricia Flórez Nisperuza, } \\
\text { Julio César Páez García, Carlos } \\
\text { Mario Fernández, Jhan Freddy } \\
\text { Salgado }\end{array}$ & 2019 \\
\hline 03 & $\begin{array}{l}\text { Adaptação do modelo } 5 E \text { ao uso de ferramentas digitais } \\
\text { para educação: proposta para o professor de ciências }\end{array}$ & Dafne Bastida Bastida Izaguirre & 2018 \\
\hline 04 & A formação continuada do professor de Física & $\begin{array}{l}\text { Jesuína Lopes De Almeida Pacca } \\
\text { e Alberto Villani }\end{array}$ & 2018 \\
\hline 05 & $\begin{array}{l}\text { Uso de recursos TIC en la enseñanza de las matemáticas: } \\
\text { retos y perspectiva }\end{array}$ & $\begin{array}{l}\text { Andrés Mauricio } \quad \text { Grisales } \\
\text { Aguirre }\end{array}$ & 2018 \\
\hline 06 & $\begin{array}{l}\text { Calidad educativa en las instituciones de educación } \\
\text { superior: evaluación del síndrome de burnout en los } \\
\text { profesores }\end{array}$ & Janette Brito Laredo & 2018 \\
\hline
\end{tabular}




\begin{tabular}{|c|c|c|c|}
\hline 07 & $\begin{array}{l}\text { Solucionando dificultades en el aula: una estrategia } \\
\text { usando el aprendizaje basado en problemas }\end{array}$ & $\begin{array}{l}\text { Mery Luz Valderrama Sanabria, } \\
\text { Gerardo Alberto Castaño } \\
\text { Riobueno }\end{array}$ & 2017 \\
\hline 08 & $\begin{array}{l}\text { Diagnóstico del uso de las tecnologías en el proceso de } \\
\text { enseñanza y aprendizaje en la educación superior }\end{array}$ & $\begin{array}{l}\text { Rosario Lucero Cavazos Salazar; } \\
\text { Sergio Guadalupe Torres Flores }\end{array}$ & 2016 \\
\hline 09 & $\begin{array}{l}\text { Influencia de las Tecnologías de Información y } \\
\text { Comunicación en los roles e interrelaciones entre } \\
\text { estudiantes y docentes en programas presenciales de } \\
\text { educación superior }\end{array}$ & $\begin{array}{l}\text { Norma Julieth Ruiz Rodríguez, } \\
\text { Martha Ruth Mendoza Torres, } \\
\text { Luis Gabriel Ferrer }\end{array}$ & 2014 \\
\hline 10 & $\begin{array}{l}\text { Formação em saúde com vivência no Sistema Único de } \\
\text { Saúde (SUS): percepções de estudantes do curso de } \\
\text { Odontologia da Universidade Federal do Rio Grande do } \\
\text { Sul (UFRGS), Brasil }\end{array}$ & $\begin{array}{l}\text { Alexandre Favero Bulgarelli; } \\
\text { Kellyn Rocca Souza; Alexandre } \\
\text { Baumgarten; Juliana Maciel de } \\
\text { Souza; Cassiano Kuchenbecker } \\
\text { Rosing; Ramona Fernanda } \\
\text { Cerioti Toassi. }\end{array}$ & 2014 \\
\hline 11 & $\begin{array}{l}\text { Aprendizagem Significativa Crítica pela proposição } \\
\text { explicativa de analogias através do Modelo Didático } \\
\text { Analógico (MDA) }\end{array}$ & $\begin{array}{l}\text { María Elena Infante-Malachias, } \\
\text { Diana Borges dos Santos }\end{array}$ & 2013 \\
\hline 12 & $\begin{array}{l}\text { Práticas docentes na Saúde: contribuições para uma } \\
\text { reflexão a partir de Carl Rogers }\end{array}$ & $\begin{array}{l}\text { Eliana Silva Cassimiro de } \\
\text { Araújo, Vânia Maria de Oliveira } \\
\text { Vieira }\end{array}$ & 2013 \\
\hline 13 & $\begin{array}{l}\text { A Intencionalidade para a aprendizagem significativa da } \\
\text { biomecânica: reflexões sobre possíveis evidências em um } \\
\text { contexto de formação inicial de professores de educação } \\
\text { física }\end{array}$ & $\begin{array}{l}\text { Rachel Saraiva Belmont; } \\
\text { Evelyse dos Santos Lemos }\end{array}$ & 2012 \\
\hline 14 & $\begin{array}{l}\text { Exercício de avaliação da prática profissional como } \\
\text { estratégia de ensino e aprendizagem }\end{array}$ & $\begin{array}{l}\text { Maria Cristina Guimarães da } \\
\text { Costa; Cleber José Mazzoni; } \\
\text { Luzmarina Aparecida Doretto } \\
\text { Braccialli; Magali Aparecida } \\
\text { Alves de Moraes. }\end{array}$ & 2011 \\
\hline 15 & $\begin{array}{l}\text { A narrativa da prática como uma estratégia de construção } \\
\text { do conhecimento na formação superior em saúde }\end{array}$ & $\begin{array}{l}\text { Verônica Santos Albuquerque; } \\
\text { Carlos Otávio Fiúza Moreira; } \\
\text { Suzelaine Tanji; André Vianna } \\
\text { Martins. }\end{array}$ & 2010 \\
\hline 16 & $\begin{array}{l}\text { O que pensam os professores sobre a função da aula } \\
\text { expositiva para a aprendizagem significativa }\end{array}$ & $\begin{array}{l}\text { Jesuína Lopes de Almeida } \\
\text { Pacca; Anne Louise Scarinci }\end{array}$ & 2010 \\
\hline 17 & $\begin{array}{l}\text { CD-ROM como instrumento de aprendizagem } \\
\text { significativa sobre a bioespeleologia sergipana }\end{array}$ & $\begin{array}{l}\text { Christiane Ramos Donato \& } \\
\text { Mário André Trindade Dantas }\end{array}$ & 2009 \\
\hline 18 & $\begin{array}{l}\text { Ambulatório de genética médica na Apae: experiência no } \\
\text { ensino médico de graduação }\end{array}$ & $\begin{array}{l}\text { Débora Gusmão Melo; Marcelo } \\
\text { Marcos Piva Demarzol; Jair } \\
\text { Huber }\end{array}$ & 2008 \\
\hline 19 & $\begin{array}{l}\text { Uso de um Texto de apoio como Organizador Prévio: } \\
\text { Combinatória para o Ensino Fundamental e Ensino } \\
\text { Médio1 }\end{array}$ & $\begin{array}{l}\text { José Roberto da Silva, Marco } \\
\text { Antonio Moreira }\end{array}$ & 2007 \\
\hline
\end{tabular}

